\title{
Vegetative Propagation of Bombax costatum Pellegr. \& Vuillet (Malvaceae) by Root Segments Cuttings: Effects of Mother Tree Diameter and Origin of Cuttings
}

\author{
Oumarou Haman Zéphirin ${ }^{1}$, Hamawa Yougouda ${ }^{1,2}$, Tsobou Roger ${ }^{1,3}$, Dangai Yohana ${ }^{1}$, \\ Binwe Jean Baptiste ${ }^{1}$, Madi Amedi Damba Rodrigue ${ }^{1}$, Abdoulaye Herbert ${ }^{1}$, \\ Wangbitching Jean De Dieu ${ }^{1}$, Fawa Guidawa ${ }^{1}$, Mapongmetsem Pierre Marie ${ }^{1, ~ * ~}$ \\ ${ }^{1}$ Laboratory of Biodiversity and Sustainable Development, Faculty of Sciences, University of Ngaoundere, Ngaoundere, Cameroon \\ ${ }^{2}$ Polytechnic School, University of Maroua, Maroua, Cameroon \\ ${ }^{3}$ Faculty of Sciences, University of Dschang Dschang, Cameroon
}

Email address:

piermapong@yahoo.fr (M. P. Marie)

${ }^{*}$ Corresponding author

\section{To cite this article:}

Oumarou Haman Zéphirin, Hamawa Yougouda, Tsobou Roger, Dangai Yohana, Binwe Jean Baptiste, Madi Amedi Damba Rodrigue, Abdoulaye Herbert, Wangbitching Jean De Dieu, Fawa Guidawa, Mapongmetsem Pierre Marie. Vegetative Propagation of Bombax costatum Pellegr. \& Vuillet (Malvaceae) by Root Segments Cuttings: Effects of Mother Tree Diameter and Origin of Cuttings. American Journal of Agriculture and Forestry. Vol. 7, No. 6, 2019, pp. 248-258. doi: 10.11648/j.ajaf.20190706.12

Received: June 23, 2019; Accepted: August 6, 2019; Published: October 11, 2019

\begin{abstract}
B$. costatum is a local species of great socio-economique importance whose flowers are consummed and commercialized in local and regional market. Despite its economical and social value in local communities, it is still in the wild stand in the Guinean Savannah Highlands of Cameroon. The objective of the study is to contribute to its domestication by root segments cuttings. Root system of the mother trees was carefully excavated and the root samples $(0.5-1 \mathrm{~kg})$ for the carbohydrate analysis were collected monthly throughout the year. In addition, a total of 180 root segments cuttings (RSC) were collected from 20 parent trees of different diameters at breast height $(\mathrm{dbh})(15-30 \mathrm{~cm} ; 30.1-45 \mathrm{~cm}$ and $>45 \mathrm{~cm})$ in «Gamba» and «Karna manga». The experimental design explorated was a split - plot with 03 replicates. The trial was conducted in a non mist polypropagator. The results reveal that among the carbohydrates evaluated, fructose decreased from the dry to the rainy seasons while soluble and total sugars move in inverse order. The first buds appear 08 weeks after planting. At the end of the essay, the highest budding rate $(81.11 \pm 19.65 \%)$ was obtained in root segments cuttings from Karna manga against $68.33 \pm 34.88 \%$ in RSC from mother trees of dbh $30.1-45 \mathrm{~cm}$. Regarding the origin of root segments cuttings by dbh of parent trees interaction, the budding rate varied significantly from $36.66 \pm 5.77 \%$ in RSC from mother trees of dbh $15.1-30 \mathrm{~cm}$ originated from Gamba to $100 \pm 0 \%$ in those from parent trees of the same dbh in Karna manga $(0.0046<0.01)$. The average height of leafy shoots varied from $8.28 \pm 5.23 \mathrm{~cm}$ in RSC from Gamba to $11.91 \pm 7.35 \mathrm{~cm}$ in those from Karna manga. The rooting rate fluctuated from $3.33 \pm 2.53 \%$ in root segments cuttings from mother trees of dbh $30.1-45 \mathrm{~cm}$ and dbh $>45 \mathrm{~cm}$ originated respectively from Gamba and Karna manga to $50 \pm 26.45 \%$ in those from parent trees of dbh 15 - $30 \mathrm{~cm}$ from Karna manga. These results will help to elaborate appropriate domestication and conservation strategies of the species.
\end{abstract}

Keywords: B. costatum, Carbohydrates, Domestication, Vegetative Propagation, RSC, Root Ability

\section{Introduction}

Bombax costatum, locally known as "Djoye"' in peulh, is among the most socio-economic important tree species of the Guinean Savannah Highlands (GSH) of Adamawa in
Cameroon $[1,2]$. Plants that bear edible Non Timber Forest Products are subjected to abuse by the operators. They offer flowers and fruits that are regularly harvested and consumed or sold in local and regional markets [3]. Different parts of the species are utilized in folk medicine, handicraft and 
feeding $[4,5]$. The wood is valued in the manufacture of kitchen tools. The bark of the tree is used in the treatment of wounds and diarrhea [6] as well as facilitate childbirth [7, 8]. Leaves nurse fever while flowers are used as condiment [3]. Dried immature fruits are used as spices [9]. The great utility of the species can become harmful, although, it can be an asset in favor of its promotion and the acquaintances of the establishment modality of germplasm development. In the $\mathrm{GSH}$, the plant is overexploited and most trees are unable to bear fruits. Lack of seeds limits the possibility to propagate the tree $[2,10]$. In the near future, if nothing is done, it could disappear and it would be a great loss for the population of this zone. Therefore its conservation is urgent. Absence of informations related to its conservation is an important handicap for the population. It was reported in Burkina Faso that $B$. costatum can be propagated vegetatively $[11,12]$. In the agro-ecological conditions of the GSH of Cameroon, numerous works have been carried out on the propagation by root segments cuttings (RSC) of many species [13-17]. However, none of these works was focused in B. costatum. The main purpose of the present study was to fill the gaps and contribute to the domestication of the species. More specifically, to evaluate seasonal fluctuation of carbohydrates and the relationship between carbohydrate contents and ability of root segments cuttings to regenerate; to assess the influence of the origin of parent trees as well as its diameter at breast height on the ability of RSC to form adventitious buds and roots. Our hypothesis was that sprouting and rooting efficiency of root cuttings taken from parent trees are directly related to carbohydrate concentration. In addition to a test of this putative relationship, we wanted to profile the fluctuation of carbohydrates during the seasonal cycle of one year.

\section{Materials and Methods}

\subsection{Study Site}

Root segments cuttings (RSC) used in the study were sampled in 20 genotypes from «Gamba» and «Karna manga» located in Guinean Savannah Highlands of Adamawa region. The climate is guinean type with a dry season (November to March) and rainy season (April to October) [18]. For the period of 2008-2017, the average annual rainfall and temperature were respectively $1467.13 \mathrm{~mm}$ and $23.28^{\circ} \mathrm{C}$. The area is covered with shrub and / or woody savannah dominated by Daniellia oliveri and Lophira lanceolata [19]. The evolution of the vegetation is severely hampered by anthropic activities [20]. The soil of the region is constituated in majority of red ferralitic structure developped on old basalt [21]. This region is constituated of multicultural ethnic groups among which the most dominant are Foulani, Mboum, Pere, Niza'a and Dourou [18].

\subsection{Sampling of Roots and Carbohydrates Analyses}

Due to the importance of carbohydrates as a source of energy and building blocks of macromolecules during the root development, the first step of this study focus on change of carbohydrate concentrations in mother trees during the year. They are therefore important for root formation. It is often considered exclusively that the availability of carbohydrates as an energetic requirement to drive rooting and together with phytohormones [22]. Root system of mother trees was carefully excavated and root samples $(0.5-1 \mathrm{~kg})$ of $2 \mathrm{~cm}$ diameter were collected monthly throughout the year (January-December) for carbohydrate analysis. The samples were dried in ambient temperature $\left(23.28^{\circ} \mathrm{C}\right)$, then ground in a mill and stored in airtight plastic bags. Analysis of carbohydrates (soluble sugar, total sugar and fructose) were carried out through Acid 2-hydroxy - 3,5 - dinitrobenzoique method in standard procedures [23].

\subsection{Preparation and Cultivation of Root Segments Cuttings}

The experiment was conducted in a non mist polypropagator installed at the nursery of the Laboratory of Biodiversity and Sustainable Development of the University of Ngaoundere (Altitude: $1079 \mathrm{~m}$; Latitude North: $7^{\circ} 24^{\prime}$; Longitude East: $13^{\circ} 32^{\prime}$ ). A polypropagator is raised under a shed with roof in corrugated iron where 06 white transparent sheets where inserted. It is subdivided in three compartments thus corresponding to three replications. This low-cost installations provide conditions conducive to rooting cuttings. The system is simple, inexpensive and easy to operate. The polypropagator is a wooden frame enclosed in a single sheet of polythene such that the base is completely water tight. The frame was covered tightly with single piece of polythene and a closely-fittting lid. It was $3 \mathrm{~m}$ long versus $1 \mathrm{~m}$ wide and $1 \mathrm{~m}$ height at the back and $0.5 \mathrm{~m}$ in the main face. The base of polypropagator was covered with a thin layer of sand to protect the polythene and large stones were placed on top of the sand to a depth of $10-15 \mathrm{~cm}$. This was then covered by successive layers of small stones and gravel to a total depth of $20 \mathrm{~cm}$. The saturated layers of stones and gravel were covered by a rooting medium composed with $50 / 50 \%$ homogeneous mixtures of sand/sawdust which was shown performant in the previous studies [16, 17]. The rooting media remained moist by capillarity and could be dampened from the above as necessary. This resulted in a permanently humid environment throughout the propagation period [24]. The relative humidity prevailing inside the polypropagator varied from $80-100 \%$ while the temperature varied from $28-30^{\circ} \mathrm{C}$.

Preferred characteristics of local populations were considered in the selection of the 20 genotypes used: good sanitary conditions, regular production and low branching. A total of 180 root segments cuttings (RSC) were taken in «Gamba» and «Karna manga» from the same trees as the root samples for the cabohydrate analyses. In each of these sites, the partial excavation was undertaken in root system of mother trees of different diameters at breast height (dbh). The RSC of about $2 \mathrm{~cm}$ diameter, $20 \mathrm{~cm}$ long [16] were wrapped in a moistened newsprint paper and transported in a cooler to the nursery. Root segments cuttings of the diameter 
similar to those typically used in carbohydrate analyses, arrived at the nursery on the same day. They were inserted vertically in rooting medium (homogenous mixture of sand/sawdust $50 / 50 \%$ ). A $1 \mathrm{~cm}$ notch was incised at the distal end of each root segments cuttings [25]. The essay was watered twice a day (morning and evening) using a hand sprayer. An open cylinder made of PVC pipe was inserted vertically into the medium and stones. This pipe was used as the filling point for the water and allowed a regular check of the water table. A root segments cuttings with at least one leafy shoot is considered budded. A RSC was considered as rooted if the length of the root was greater than $1 \mathrm{~cm}$ [26]. Rooted RSC were inserted vertically in large perforated polyethylene bags $(27 \mathrm{~cm}$ diameter $\times 40 \mathrm{~cm}$ height $)$ containing the homogenous mixture of arable soil / sawdust which was found performant. These bags were introduced in acclimatization propagators and watered mornings and evenings. During the acclimatation phase, the propagators were left open each night during a month. Watering was then reduced to once a day. After this phase, the plants were transferred to the open field.

\subsection{Experimental Design and Data Analysis}

Globally, the experimental design exploited for the two trials was a Split-plot each.

For the carbohydrate analysis, the main treatment was season (beginning of the dry season, end of the dry season, beginning of the rainy season and end of the rainy season) and the sub-treatment was represented by sugars (fructose, soluble sugar and total sugar). The number of replications was two.
Regarding the vegetative propagation by root segments cuttings, the origin (Gamba, Karna manga) of RSC was the main treatment while the mother trees diameter $(15-30 \mathrm{~cm}$; $30,1-45 \mathrm{~cm}$ and $>45 \mathrm{~cm}$ ) corresponded to sub-treatment. The number of replications was three while the experimental unit was made up of 10 cuttings. A total of 180 RSC $(2 \times 3 \times 3 \times 10)$ were prepared for the experiment. The following parameters were determined: the rate of budding, the number and the height of leafy shoot and the number of leaves per leafy shoot, the rooting rate, the number and the length of roots. Budding corresponds to bud burst of latent buds that emit one or more leafy shoots on the RSC; the rate of rooting (equated to the succes rate of root segments cuttings), the pole on which the leafy shoots were developped (distal or proximal pole) was determined. The distal pole contrarily to proximal corresponds to the extremity of the root segments cuttings which was originally located farthest from the base of the parent tree. For this part, data on rooting were collected at the end of the experiment ( 24 weeks).

Quantitative data were subjected to an analysis of variance and Post-hoc comparisons were done with the Duncan's Multiple Range Test when significant mean effects were noted. All the analysis were performed using the Statgraphics 5.0 software.

\section{Results}

In vegetative propagation by root segments cuttings (RSC), adventitious bud and root formation are prerequisite of successfull propagation.

\subsection{Seasonal Fluctuation of Root Carbohydrates in Mother Trees}

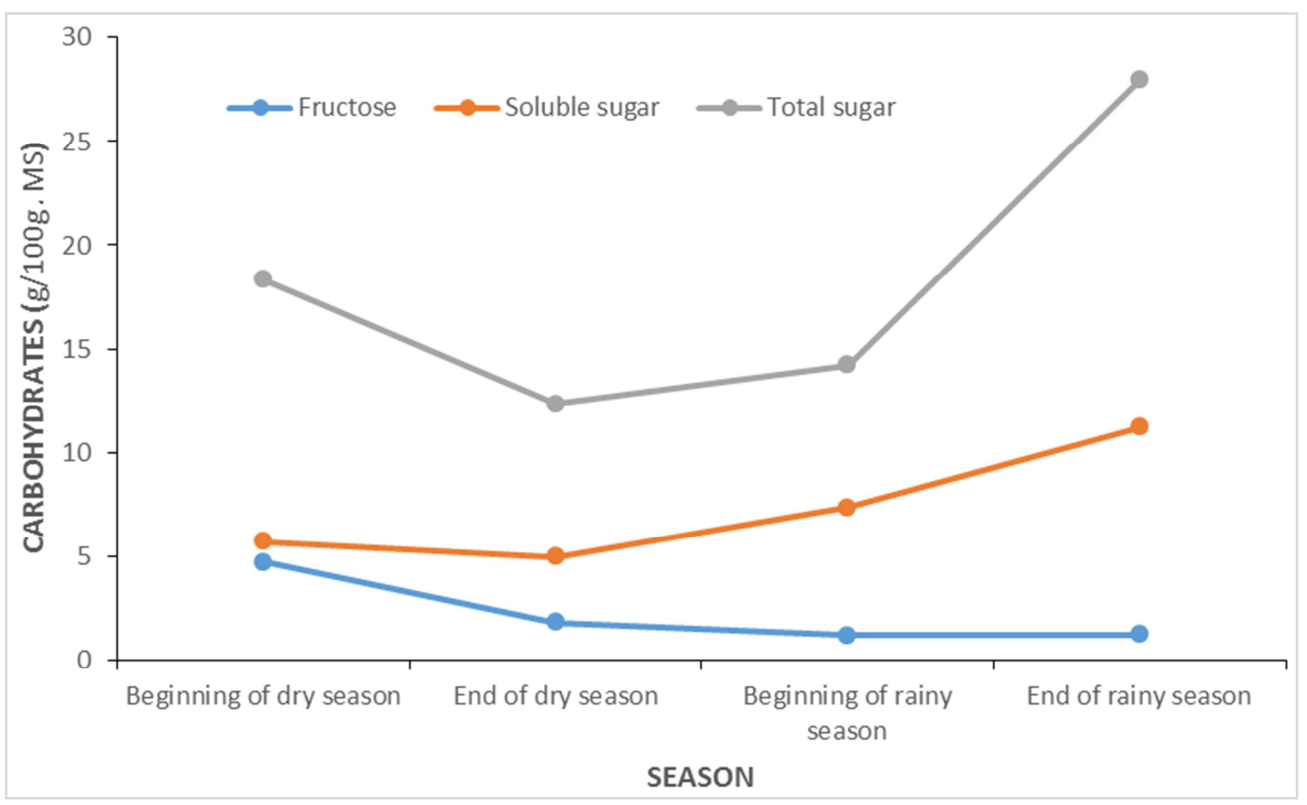

Figure 1. The seasonal fluctuation of soluble sugar, total sugar and fructose in roots of parent trees in savannah conditions.

Root concentrations of carbohydrates clearly fluctuated under field conditions throughout the year, being highest at the end of rainy season and lowest at the end of dry season except for fructose. The analysis of variance indicated that 
the time of sampling condition of the mother trees account significantly for over $99.99 \%$ of total variation in fructose, soluble and total sugar concentrations among root samples $(0.0000<0.001)$. Regarding the seasons, there was also a significant difference $(0.0000<0.001)$ as well as the carbohydrate by season interaction $(0.0000<0.001)$. Thus, the seasonal variation of fructose content was different, high in the beginning of dry season $(4.71 \mathrm{~g} / 100 \mathrm{~g} . \mathrm{MS})$ and lowest $(1.18 \mathrm{~g} / 100 \mathrm{~g} . \mathrm{MS})$ in the beginning of the rainy season. The soluble sugar increased from the beginning of the dry season $(5.58 \mathrm{~g} / 100 \mathrm{~g} . \mathrm{MS})$ to the end of rainy season (11.18 g/100g.MS). In the beginning of the dry season (from 18.32 g/100g.MS), the value of total sugar decreased to 12.24 $\mathrm{g} / 100 \mathrm{~g} . \mathrm{MS}$ in the end of dry season then increased up to $27.96 \mathrm{~g} / 100 \mathrm{~g}$.MS at the end of rainy season (Figure 1). Analogous variations were reported in hybrid aspen clones [27]. The authors argued that carbohydrate reserves varied during the annual cycle of plants, with root carbohydrate concentrations being highest during the dormant period and reducing in the spring when they are transported to the shoot for bud burst and vegetative growth.

Among the three carbohydrates evaluated, fructose decreased from the dry to the rainy seasons while soluble and total sugars move in inverse order. Many experiments have indicated that the source of carbohydrates is critical for rooting. Therefore, they conclude that a large amount of carbohydrates is essential to initiate and accompany the rooting process $[28,29]$.

During this process, carbohydrates act as a source of energy and as constitutive elements for the newly formed cells. Based on the trend of fructose, RSC for the present trial were collected on the mother trees during the end of the dry season. For the coming trials, RSC will be collected during the rainy season.

\subsection{Effect of Origin of Root Segments Cuttings and Dbh of Mother Trees on Budding}

\subsubsection{Rate of Budding}

The root segments cuttings were put in culture at the beginning of the dry season and the trial lasted 24 weeks. The first buds were observed after 08 weeks in cuttings originated from Gamba in parent trees of dbh $30.1-45 \mathrm{~cm}$. All RSC have developped leafy shoot without formation of adventitious roots (Figure 2 ).

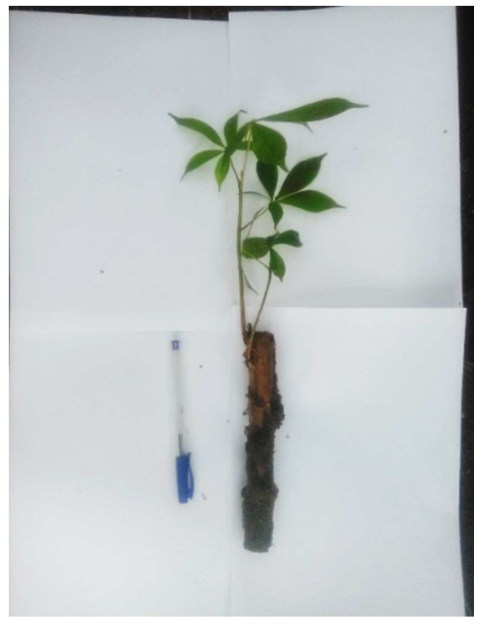

Figure 2. Root segments cutings without adventitiuos roots.

Concerning the origin of root segments cuttings, at the end of the essay, the rate of budding varied from $44.44 \pm 14.24 \%$ in root segments cuttings from Gamba to $81.11 \pm 19.65 \%$ in those from Karna manga (Figure 3). A significant difference was registered among the origins of $\operatorname{RSC}(0.0000<0.001)$.

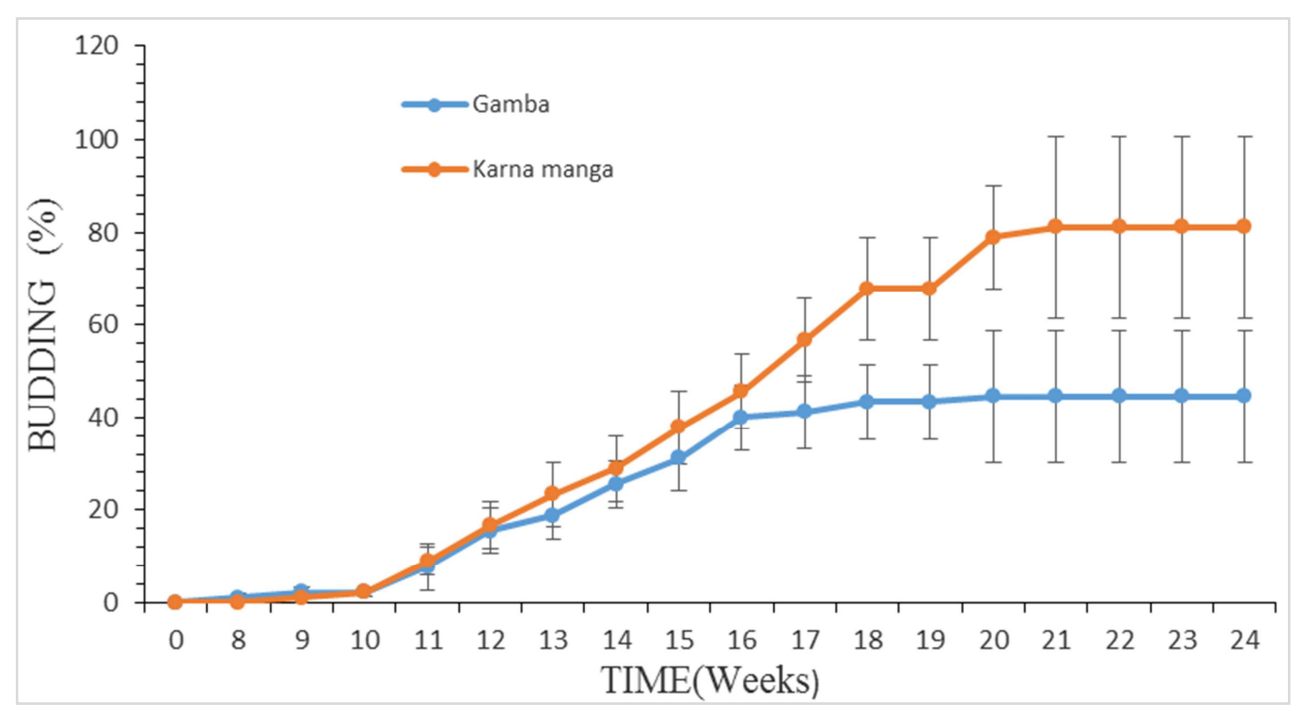

Figure 3. Rate of budding of B. costatum according the origin of root segments cuttings.

For the diameter at breast height $(\mathrm{dbh})$ of the parent trees, the rate of budding fluctuated from $51.66 \pm 11.69 \%$ in root segments cuttings collected from trees of $\mathrm{dbh}>45 \mathrm{~cm}$ to $68.33 \pm 34.88 \%$ and $68.33 \pm 24.01 \%$ in those belonging to $\mathrm{dbh}$
$15.1-30 \mathrm{~cm}$ and $30.1-45 \mathrm{~cm}$ respectively (Figure 4). A significant difference was registered among the dbh sizes of the parent trees $(0.0339<0.05)$. 


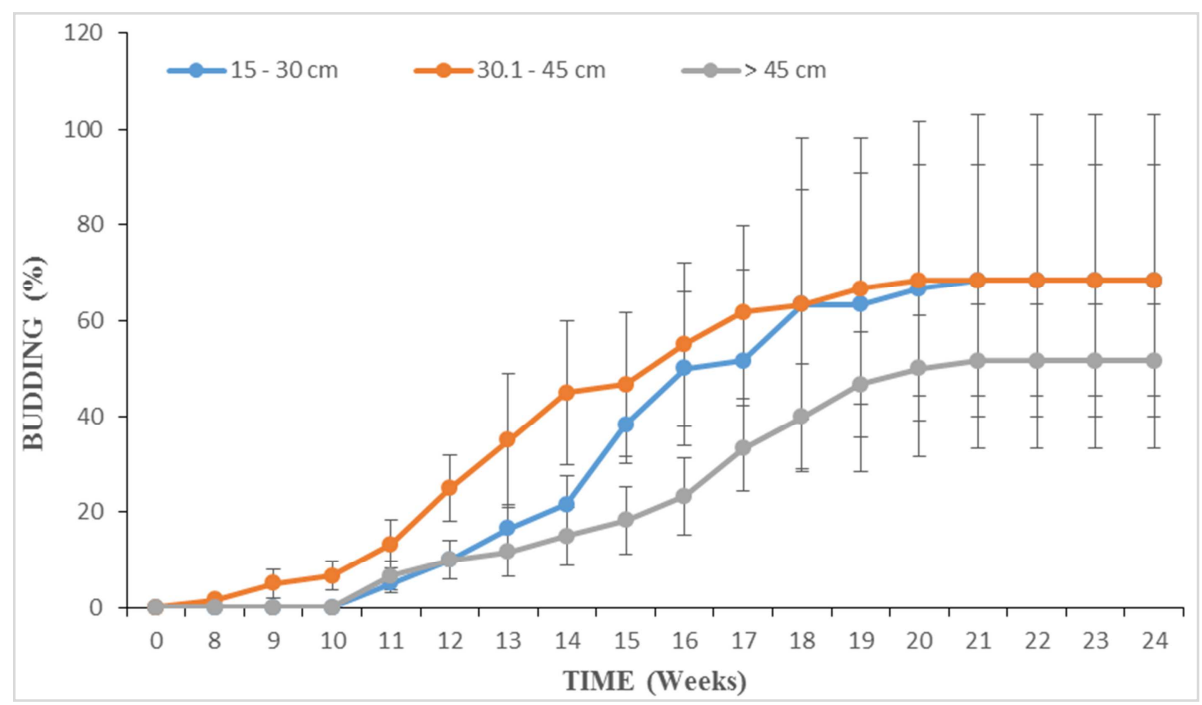

Figure 4. Rate of budding of Bombax costatum according to the dbh of parent trees.

The origin of RSC by dbh of mother trees interaction has significatively influenced the budding rate $(0.0046<0.01)$. The rate of budding varied from $36.66 \pm 5.77 \%$ in $\mathrm{RSC}$ originated from Gamba gathered on mother trees of dbh equal to $15.1-30 \mathrm{~cm}$ to $100 \pm 0 \%$ in those from Karna manga from mother trees of dbh $15.1-30 \mathrm{~cm}$ (Figure 5).

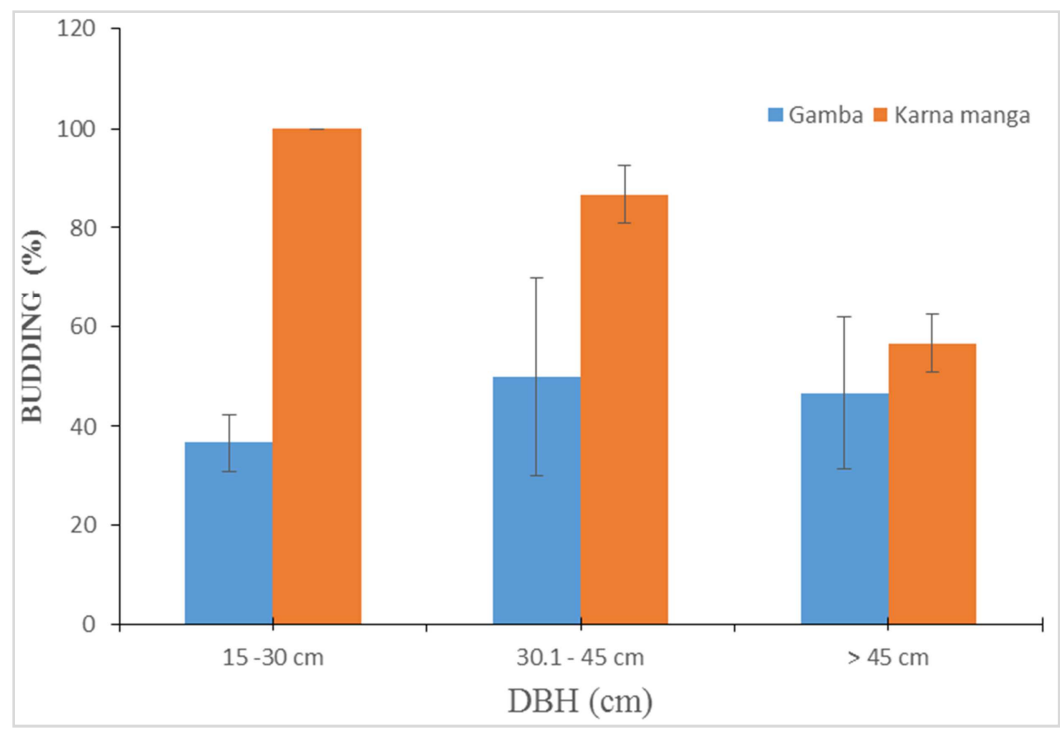

Figure 5. Budding rate of RSC according the diameter at breast height of parent trees.

\subsubsection{Number of Leafy Shoots Per Root Segment Cutting}

At the end of the experiment, the average number of leafy shoots varied from $0.84 \pm 0.28$ in RSC originated from Gamba to $1.3 \pm 0.63$ in those from Karna manga (Table 1). The origin of root segments cuttings has significatively influenced the number of leafy shoots $(0.0139<0.05)$.

Table 1. Effect of the origin of root segments cuttings on growth caracteristics of leafy shoots after 24 weeks.

\begin{tabular}{llll}
\hline Origin of RSC & Number of leafy shoots & Height of the leafy shoots (cm) & Number of leaves per leafy shoot \\
\hline Gamba & $0.84 \pm 0.28 \mathrm{~b}$ & $8.28 \pm 5.23 \mathrm{a}$ & $2.01 \pm 1.05 \mathrm{a}$ \\
Karna manga & $1.3 \pm 0.63 \mathrm{a}$ & $11.91 \pm 7.35 \mathrm{a}$ & $2.83 \pm 1.83 \mathrm{a}$ \\
P. value & 0.0139 & 0.1069 & 0.0928 \\
\hline
\end{tabular}

Means followed by the same letter are not statistically different at $5 \%$

The average number of leafy shoots varied from $0.08 \pm 0.28$ in RSC from parent trees of $\mathrm{dbh} \geq 45 \mathrm{~cm}$ to $1.28 \pm 0.59$ in those collected from parent trees of dbh equal to $15-30 \mathrm{~cm}$
(Table 2). Contrarily to the effect of origin, there was no significant diffrence between dbh of mother trees $(0.0742>$ $0.05)$. 
Table 2. Effect of dbh of mother trees on growth caracteristics of leafy shoots after 24 weeks.

\begin{tabular}{llll}
\hline Dbh $(\mathbf{c m})$ & Number of leafy shoots & Height of the leafy shoots (cm) & Number of leaves per leafy shoot \\
\hline $15-30$ & $1.28 \pm 0.59$ & $12.65 \pm 8.45$ & $3.18 \pm 2.04$ \\
$30-45$ & $1.13 \pm 0.61$ & $8.66 \pm 4.67$ & $2.08 \pm 1.07$ \\
$>45$ & $0.8 \pm 0.28$ & $8.97 \pm 6.08$ & $2 \pm 1.16$ \\
P. value & 0.0742 & 0.2597 & 0.0955 \\
\hline
\end{tabular}

$\mathrm{Dbh}=$ Diameter at breast height

Regarding the origin by dbh of mother trees interaction, the average number of leafy shoots fluctuated from $0.6 \pm 0.1$ in root segments cuttings harvested on mother trees of $\mathrm{dbh}>45 \mathrm{~cm}$ from Karna manga to $1.8 \pm 0.2$ in $\mathrm{RCS}$ from parent trees of dbh $15-30 \mathrm{~cm}$ originated from the same locality (Table 3). There was a significant diffrence for the origin by dbh interaction $(0.0074<0.01)$.

Table 3. Number of leafy shoots for origin of root segments cuttings by dbh of mother trees interaction.

\begin{tabular}{|c|c|c|c|c|}
\hline Dbh $(\mathrm{cm}) /$ Origin & $15-30$ & $30.1-45$ & $\geq 45$ & Mean \\
\hline Gamba & $0.76 \pm 0.21 \mathrm{a}$ & $0.76 \pm 0.38 \mathrm{a}$ & $1 \pm 0.26 \mathrm{ab}$ & $0.84 \pm 0.28$ \\
\hline Karna manga & $1.8 \pm 0.2 b$ & $1.5 \pm 0.61 \mathrm{~b}$ & $0.6 \pm 0.1 \mathrm{a}$ & $1.3 \pm 0.31$ \\
\hline Mean & $1.28 \pm 0.21$ & $1.13 \pm 0.49$ & $0.8 \pm 0.18$ & $1.07 \pm 0.29$ \\
\hline
\end{tabular}

Means followed by the same letter are not statistically different at $5 \%$

\subsubsection{Height of Leafy Shoots}

The origin of root segments cuttings has not significatively influenced the height of leafy shoots $(0.1069>0.05)$. The average height of leafy shoots varied from $8.28 \pm 5.23 \mathrm{~cm}$ in root segments cuttings originated from Gamba to $11.91 \pm 7.35$ $\mathrm{cm}$ in those from Karna manga (Table 1).

The average height of leafy shoots ranged from $8.66 \pm 4.67$ $\mathrm{cm}$ in RSC collected from mother trees of dbh $30.1-45 \mathrm{~cm}$ to $12.65 \pm 8.45 \mathrm{~cm}$ in those gathered on mother trees of $\mathrm{dbh}$
$15-30 \mathrm{~cm}$ (Table 2). Nevertheless, the dbh of mother trees has no significant difference among the height of leafy shoots $(0.1069>0.05)$.

The average height of leafy shoots varied from $4.87 \pm 1.72 \mathrm{~cm}$ in RSC from parent trees of $\mathrm{dbh} \geq 45 \mathrm{~cm}$ originated from Karna manga to $19.3 \pm 6.04 \mathrm{~cm}$ in those from parent trees of dbh $15-30 \mathrm{~cm}$ of the same locality (Table 4). There was a significant diffrence for the interaction $(0.0038<0.01)$.

Table 4. Height of leafy shoots according to the origin of root segments cuttings by dbh of mother trees interaction.

\begin{tabular}{|c|c|c|c|c|}
\hline Dbh (cm) / Origin & $15-30$ & $30-45$ & $>45$ & Mean \\
\hline Gamba & $6 \pm 3.04 a$ & $5.76 \pm 3.06 a$ & $13.08 \pm 6.23 \mathrm{ab}$ & $8.28 \pm 4.11$ \\
\hline Karna manga & $19.3 \pm 6.04 b$ & $11.56 \pm 4.47 \mathrm{ab}$ & $4.86 \pm 1.72 \mathrm{a}$ & $11.90 \pm 4, .07$ \\
\hline Mean & $12.65 \pm 4.54$ & $8.66 \pm 3.76$ & $8.97 \pm 3.97$ & $10.09 \pm 4.09$ \\
\hline P.value & & 0.0038 & & \\
\hline
\end{tabular}

Means followed by the same letter are not statistically different at 5\%

\subsubsection{Number of Leaves Per Leafy Shoot}

The average number of leaves per leafy shoot oscillated between $2.01 \pm 1.05$ in RSC from Gamba and $2.83 \pm 1.83$ in those from Karna manga (Table 1). However, there was no significant difference among the origin of RSC $(0.0928>$ $0.05)$.

The average number of leaves per leafy shoot oscillated between $2 \pm 1.16$ in RSC collected from mother trees of dbh $\geq 45 \mathrm{~cm}$ and $3.18 \pm 2.04$ in those collected from parent trees of dbh 15 - $30 \mathrm{~cm}$ (Table 2). However, there was no significant difference between dbh of mother trees $(0.0955>0.05)$.

Concerning the origin by dbh of mother trees interaction, the mean number of leaves per leafy shoot fluctuated from $1.13 \pm 0.49$ in RSC from parent trees of $\mathrm{dbh} \geq 45 \mathrm{~cm}$ collected in Karna manga to $4.86 \pm 1.17$ in those from parent trees of dbh $15-30 \mathrm{~cm}$ of the same locality (Table 5). Significant diffrence existed for the interaction origin by dbh of mother trees $(0.0021<0.01)$.

Table 5. Number of leaves per leafy shoot according the origin of cuttings by dbh of mother trees interaction.

\begin{tabular}{llll}
\hline Dbh (cm) / Origin & $\mathbf{1 5 - 3 0}$ & $\mathbf{3 0 - 4 5}$ & $>\mathbf{4 5}$ \\
\hline Gamba & $1.5 \pm 0.75 \mathrm{a}$ & $1.66 \pm 1.13 \mathrm{a}$ & $2.86 \pm 0.95 \mathrm{ab}$ \\
Karna manga & $4.86 \pm 1.17 \mathrm{~b}$ & $2.5 \pm 1.05 \mathrm{ab}$ & $1.13 \pm 0.49 \mathrm{a}$ \\
Mean & $3.18 \pm 0.96$ & $2.08 \pm 1.09$ & $1.99 \pm 0.72$ \\
P.value & & 0.0021 & $2.01 \pm 0.94$ \\
\hline
\end{tabular}

Means followed by the same letter are not statistically different at 5\% 


\subsection{Effect of Origin of Root Segments Cuttings and DBH of Parent Trees on Root Formation}

\subsubsection{Rate of Rooting}

The rooting rate ranged from $10 \pm 10 \%$ in root segments cuttings from Gamba to $27.77 \pm 24.88 \%$ for those originated from Karna manga. There was significant differnce between origin of cuttings $(0.0128<0.05)$. The RSC from Karna manga produced more vigorous adventitious roots than those from Gamba (Figure 6).

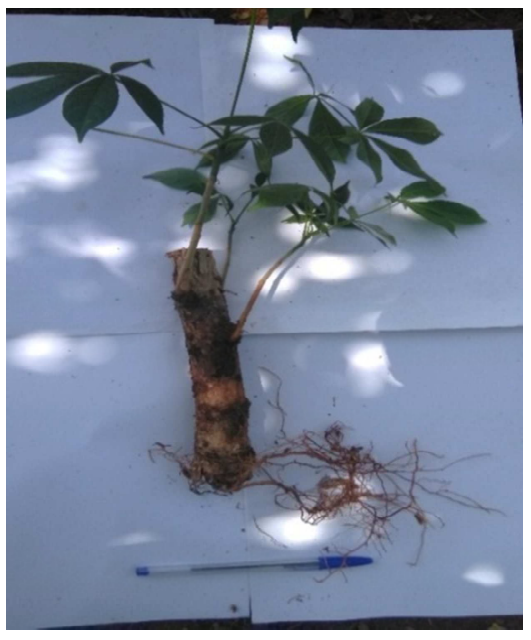

a

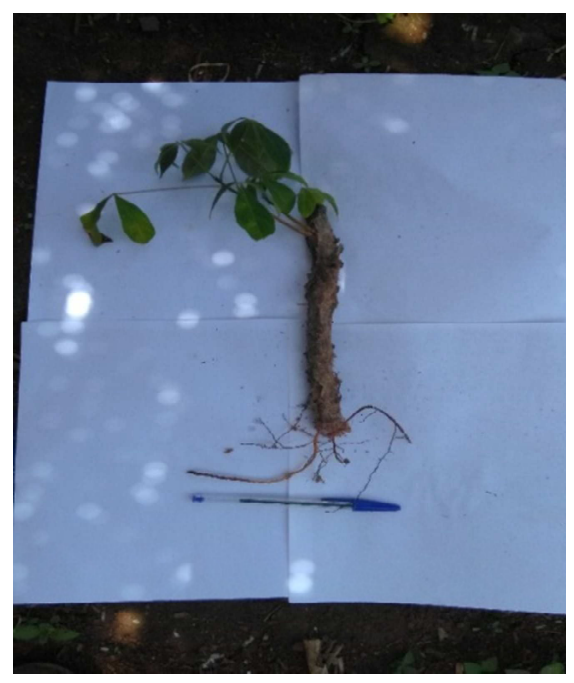

b

Figure 6. RSC rooted: from Karna manga (a); from Gamba (b).

For the diameter at breast height of the parent trees, the rooting rate varied from $11.66 \pm 9.57 \%$ in root segments cuttings from trees of $\mathrm{dbh} \geq 45 \mathrm{~cm}$ to $28.33 \pm 26.45 \%$ in those from trees of dbh $15-30 \mathrm{~cm}$ (Table 6). Nevertheless the dbh of mother trees has not significatively influenced the rate of rooting $(0.1127>0.05)$.

Table 6. Effect of dbh of mother trees on the rate of rooting.

\begin{tabular}{lllll}
\hline Dbh (cm) & $\mathbf{1 5}-\mathbf{3 0}$ & $\mathbf{3 0 . 1}-\mathbf{4 5}$ & $\mathbf{> 4 5}$ & Mean \\
\hline Rooting (\%) & $28.33 \pm 26.45$ & $16.66 \pm 16.33$ & $11.66 \pm 9.57$ & $18.88 \pm 17.45$ \\
\hline
\end{tabular}

Regarding, the origin of cuttings by dbh parent trees interaction, there was significant difference between the origins of $\operatorname{RSC}(0.0048<0.01)$. The rate of rooting fluctuated from $3.33 \pm 2.53 \%$ in root segments cuttings from mother trees of dbh $30.1-45 \mathrm{~cm}$ and $\mathrm{dbh}>45 \mathrm{~cm}$ originated respectively from Gamba and Karna manga to $50 \pm 26.45 \%$ in those from parent trees of dbh $15-30 \mathrm{~cm}$ from Karna manga (Figure 7). The combination between dbh of parent and their origin improved significantly the rate of rooting.

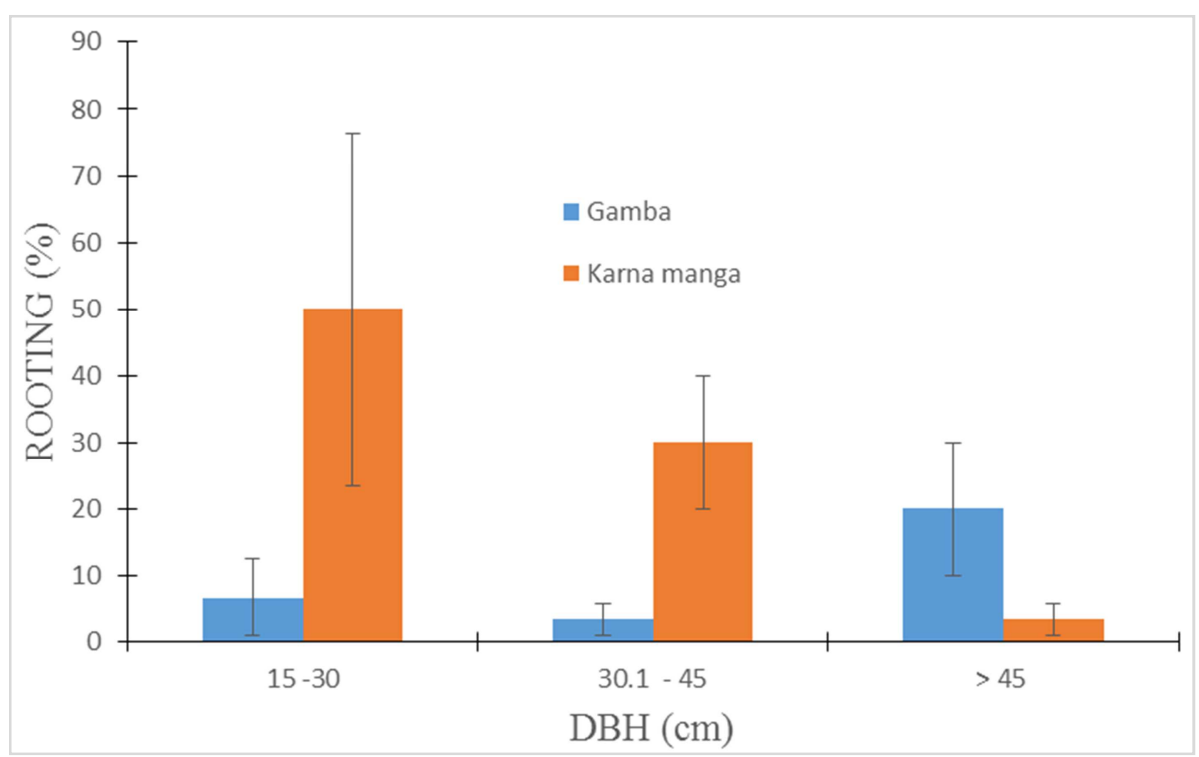

Figure 7. Root rate of RSC according the diameter at breast height of parent trees. 


\subsubsection{Number of Roots}

The average number of roots per root segment cutting varied from 2.61 \pm 2.06 in root segments cuttings from Gamba to $2.79 \pm 1.65$ in those from Karna manga. Nevertheless there was no significant diffrence between origins of RSC $(0.8128>0.05)$. The number of roots per root segment cutting was very low.

At the end of the essay, the average number of roots per RSC varied from $2.46 \pm 0.55$ in RSC from mother trees of dbh $30.1-45 \mathrm{~cm}$ to $3.07 \pm 0.44$ in those harvested on parent trees of dbh equal to $15-30 \mathrm{~cm}$ (Table 7). However, the dbh of parent trees has not significatively impacted the number of roots $(0.7949>0.05)$.

Table 7. Effect of origin of RSC on growth characteristics of roots.

\begin{tabular}{lll}
\hline Origin of RSC & Number of roots & Length of roots $(\mathbf{c m})$ \\
\hline Gamba & $2.61 \pm 2.06$ & $2.48 \pm 1.87$ \\
Karna manga & $2.79 \pm 1.65$ & $3.41 \pm 2.52$ \\
Mean & $2.7 \pm 1.85$ & $2.95 \pm 2.19$ \\
P.value & 0.8128 & 0.3374 \\
\hline
\end{tabular}

Regarding, the origin by dbh of parent trees interaction, the number of roots varied from $1 \pm 0.12$ in RSC of mother trees of dbh $30.1-45 \mathrm{~cm}$ from Gamba to $3.92 \pm 0.38$ in those of dbh $30.1-45 \mathrm{~cm}$ from Karna manga (Table 8). However there was significant diffrence for the interaction $(0.0449>0.05)$.

Table 8. Number of roots according the interaction origin of RSC *dbh of mother trees.

\begin{tabular}{lllll}
\hline Origin / Dbh (cm) & $\mathbf{1 5 - 3 0}$ & $\mathbf{3 0 . 1}-\mathbf{4 5}$ & $>\mathbf{4 5}$ & Mean \\
\hline Gamba & $3 \pm 2.65 \mathrm{~b}$ & $1 \pm 0,12 \mathrm{a}$ & $3.83 \pm 2.31 \mathrm{~b}$ & $2.61 \pm 1.69$ \\
Karna manga & $3.15 \pm 0,45 \mathrm{~b}$ & $3.92 \pm 0,38 \mathrm{~b}$ & $1.33 \pm 0,31 \mathrm{a}$ & $2.8 \pm 0.38$ \\
Mean & $3.07 \pm 1.55$ & $2.46 \pm 0.25$ & $2.58 \pm 1.31$ & $2.71 \pm 1.04$ \\
P.value & & 0.0449 & & \\
\hline
\end{tabular}

\subsubsection{Length of Roots}

Concerning the length of roots, it oscillated between $2.48 \pm 1.87 \mathrm{~cm}$ in root segments cuttings from Gamba to $3.41 \pm 2.52 \mathrm{~cm}$ in those of Karna manga (Table 7). However, there was no significant diffrence between origins of RSC $(0.3374>0.05)$.

The length of roots varied from $2.46 \pm 1.92 \mathrm{~cm}$ in RSC of mother trees of $\mathrm{dbh}>45 \mathrm{~cm}$ to $3.77 \pm 2.74 \mathrm{~cm}$ in those from mother trees of dbh 15-30 cm (Table 9). However, the dbh of parent trees has not significatively influenced the length of roots $(0.4729>0.05)$.

Table 9. Effect of dbh of mother trees on growth characteristics of roots.

\begin{tabular}{lll}
\hline Dbh $(\mathbf{c m})$ & Number of roots & Length of roots $(\mathbf{c m})$ \\
\hline $15-30$ & $3.07 \pm 0.44$ & $3.77 \pm 2.74$ \\
$30.1-45$ & $2.46 \pm 0.55$ & $2.59 \pm 2.03$ \\
$>45$ & $2.58 \pm 0.63$ & $2.46 \pm 1.92$ \\
Mean & $2.71 \pm 0.54$ & $2.94 \pm 2.23$ \\
P.value & 0.7949 & 0.4729 \\
\hline
\end{tabular}

Concerning the origin by dbh of parent trees interaction, the length of roots ranged from $1.22 \pm 1.12 \mathrm{~cm}$ in RSC of parent trees of dbh $30.1-45 \mathrm{~cm}$ from Gamba to $5.02 \pm 3.05$ $\mathrm{cm}$ in those from parent trees of dbh $15-30 \mathrm{~cm}$ in Karna manga (Table 10). The dbh of parent trees by origin interaction has no significant difference among the length of roots $(0.0740<0.05)$.

Table 10. Length of roots according the interaction origin of $R S C^{*} d b h$ of mother trees.

\begin{tabular}{lllll}
\hline Origin / Dbh (cm) & $\mathbf{1 5 - 3 0}$ & $\mathbf{3 0 . 1 - 4 5}$ & $\mathbf{> 4 5}$ & Mean \\
\hline Gamba & $2.53 \pm 2.21$ & $1.22 \pm 1.12$ & $3.68 \pm 0.31$ & $2.47 \pm 1.22$ \\
Karna manga & $5.02 \pm 3.05$ & $3.96 \pm 0.35$ & $1.25 \pm 1.16$ & $3.41 \pm 1.52$ \\
Mean & $3.77 \pm 2.63$ & $2.59 \pm 0.74$ & $2.46 \pm 0.74$ & $2.94 \pm 1.37$ \\
P.value & & 0.0740 & & \\
\hline
\end{tabular}

\subsubsection{Polarity of Root Segments Cuttings}

The leafy shoots were developed in proximal $(86.72 \%)$ and median $(13.28 \%)$ poles. The whole root was formed in distal position $(100 \%)$.

\section{Discussion}

\subsection{Carbohydrates}

The root segments cuttings (RSC) were collected in the beginning of the dry season mainly in December considering the amount of fructose. Among the carbohydrates analysed, only fructose was at its peak in the aforementionned period while soluble and total sugars reached at theirs at the end of rainy season. Fructose is known to facilitate root fomation in various species such as Nauclea diderrichii, Stevia rebaudiana and Morus alba [29-31]. Others observed that glucose give the best result in Rosa rugosa [32]. Rooting success is associated with low pre-severance starch and water-soluble sugar concentrations and greater total watersoluble carbohydrates [33]. Clearly, roots to be used for regeneration, should be taken at the time of maximum carbohydrate accumulation. The constant sugar levels maintained by all regenarating RSC despite depletion of reserves, indicate a mechanism for maintaining a minimum metabolic sugar level [34].

$B$. costatum is a deciduous tree which shade off leaves during the dry season. During leaf fall, carbohydrates moved into the roots of mother trees and rapidly converted to polysaccharides. The species analysed in this study displayed contrasting seasonal changes of plant carbohydrates. Indeed, during the rainy season, leaves accumulated soluble and total sugar while fructose greatly declined. Conversely, photosynthetic capacity declined from the beginning to the end of dry season. Thus, as reduced photosynthetic capacity induced leaf senescence, fructose content in leafy Bombax leaves increased. The most likely explanation is that carbohydrate was mobilized during leaf senescence for translocation to roots of the mother trees. However, the same carbohydrate can give very controversial effect according to the species. It is postulated that each step is controlled in different ways by balances of hormones, inhibitors and other biochemicals. Root formation in cuttings is a complex 
phenomenon in which there are at least three distinct steps: callus formation; differentiation within callus resulting in root initiation; and root growth [35]. The response of root segments cuttings, collected during the dry season to the different treatments did not form callus but confirm that budding and rooting are correlated to the large amount of soluble carbohydrates which suddenly decreased at the end of the dormancy period. Similar to soluble sugar (11.18g.MS $/ 100 \mathrm{~g})$ during the rainy season, the amount of total sugar increased till an optimum (27.96g.MS/100g). Contrarily to our expectations, fructose was the only carbohydrate that had strong correlation with the sprouting efficiency of root segments cuttings. The origin by dbh of parent trees interation improved the sprouting of RSC up to $100 \%$. Though, clearly, fructose levels do not entirely explain the root sprouting efficieny found in this study despite the fact that soluble sugar and total sugar reached their optimum during the rainy season. Lack of a high rooting response during the dry season may be attributed to the reduction in the endogenous level of auxin or nutritional status of the cuttings [36]. The rooting process is a high demanding carbohydrates process and in our experiment the carbohydrate content in cuttings showed an overall decrease during the rooting process. However, the interaction between origin and dbh of mother trees improved the rooting potential of RSC up to $50 \%$.

\subsection{Budding and Rooting}

The first buds in RSC of B. costatum appeared 08 weeks after planting. This latent period has given conflicting results. It disagreed those obtained in Burkina Faso on the same species [11] as well as those in Detarium microcarpum in the aforementioned country [25]. Nevertheless, it corroborated those in Vitex doniana in Cameroon [14]. For these authors, the appearance time of the first buds in these species was observed at four, five and eight weeks after planting. In fact, the latency period varied depending on the species, the period of harvesting of the cuttings and even following the application of hormones or not [16, 25, 27]. The sprouting process promotes the start of adventitious rooting. When the RSC sprouted, the carbohydrates supply from the leaves supported the root growth [37].

The provenance significantly influenced the rate of budding, the number of aerial buds, and the rate of rooting. The experiment was conducted in the Guinean Savannah Highlands and this would explain the fact that the budding rate and the rooting rate were high for RSC from Karna manga. Root segments cuttings tend to be more budded and rooted in the agro-ecological conditions of their environment. Indeed, Karna manga is located in the agroecological area where the essay took place. Hence a favorable response of root segments cuttings from Karna Mamga compared to those of Gamba was remarkable.

The dbh of the parent trees influenced budding. This result is shaped with that obtained in Vitex doniana in the same area [13]. These authors obtained like in the present study, a high budding rate from cutting taken from low dbh (5-10 $\mathrm{cm})$. Indeed, when the plant is young, it produced abundantly sugar and hormones responsible of budding. Budding and rooting of cuttings are influenced by the interaction of internal factors of the plant and environmental conditions [37]. A higher level of total carbohydrates was observed in an easy-to-root cultivar of chrysanthemum and it produced a greater number of roots than did the difficult to root cultivar [38].

Despite this slight variation observed, the dbh of the mother trees did not influenced the number of aerial buds, their height and the number of leaves/shoot. Root segments cuttings from parent trees of low dbh showed a slightly superiority on growth parameters, compared to those from parent trees of large dbh. Thus, the mother trees that had the dbh $15-30 \mathrm{~cm}$ produced the highest number and length of leafing shoots as well as the roots. This result is in agreement with that reported in Vitex doniana [15]. The emission of adventitious roots is low compared to the emission of buds. In fact, the emitted buds elaborated the sugars and hormones responsible for the formation of adventitious roots through the process of photosynthesis [14, 16, 25]. The origin of RSC by mother tree dbh interaction was significant and the rate of rooting was $50 \%$ suggesting the ability to produce roots. This is a remarkable result. Efficient rooting is essential, because sprouted RSC will not survive long without roots.

The concentrations of carbohydrate among which total sugar and soluble sugar except fructose were not at their optimum to induce abundant roots in the dry season. Therefore, it can be concluded that the carbohydrates were essential to initiate and accompany the rooting process. Although the effects of origin, season of gathering RSC, and size of the parent tree probably hold in a general way for $B$. costatum in the Guinean Savannah Highlands. The rooting percentage obtained in this work is low compared to that reported in Burkina Faso which was 90\% [11]. The season of collection and pedoclimatic conditions may be the explanation which could motived this variation.

Concerning the position of the buds and roots on the RSC, its polarity was conserved despite the fact that a few buds appeared in median pole.

\section{Conclusion}

Despite the relatively small influence of carbohydrate noted during the rooting period, the present results with $B$. costatum support the theory that the physiological status of the stock plant at the time that root segments cuttings are excised is of utmost importance for the subsequent rooting process. In addition, this study demonstrated that $B$. costatum could be very easily propagated from RSC. In the present study, observations showed that, the budding and rooting of B. costatum's plantlets are affected by the origin of RSC and the diameter at breast height of the parent trees as well as their endogenous carbohydrate contents.

Further studies are required: to determine, in particular, the effect of genotype, the period of optimal concentration of carbohydrates in mother trees before harvesting RSC, type of 
optimal carbohydrate to the development of RSC, differents carbohydrates produced of RSC during the propagation process and effect of mychorhiza innoculums on sprouting and rooting.

\section{Acknowledgements}

Authors wish to express their gratitude to the Conservation Action Research Network (CARN) for the financial support. They are also indebted to anonymous reviewers for their useful comments which help to improve the quality of the paper.

\section{References}

[1] Mapongmetsem P. M. Domestication et culture des espèces d'intérêt socio-économique au Cameroun. Leçon inaugurale, Doctoriales. Université de Ngaoundéré, Cameroun, 2017. $44 \mathrm{p}$.

[2] Mapongmetsem P. M., Kapchie V. N. \& B. H. Tefempa (2012a) Diversity of local fruit trees and their contribution in sustaining the rural livelihood in the Northen Cameroon. Ethiopian Journal of Environmental Studies and Management, $5(1), 32-46$.

[3] Mapongmetsem P. M., Hamawa Y., Djeumene P., Maissele D., Kossebe C. F., Ndoum J. F., Nduryang J. B., Bebbe F., Bouba D., Wouldata S., Zigro L. \& Barbi M. Valorisation des plantes alimentaires sauvages dans les savanes soudano-guinéennes du Cameroun. In Kapseu C., Mbofung C. M. et Amvam Zollo P. H. (eds.). Développement de l'Agro-Industrie et création des richesses. Actes Conférence Internationale. Ngaoundéré, Cameroun, 2008, pp. 50-61.

[4] Mapongmetsem P. M., Nduryang B. et Fawa G. Contribution à la connaissance des produits forestiers non ligneux de la zone sudano-sahélienne du Cameroun. Kapseu C., Nzié W., Nso E., Silechi J. et Gomo (éds). Biodiversité et changements globaux du 21 au 23 juillet 2015 à Ngaoundéré, 2015, pp. 139-147.

[5] Tchingsabe O., Ngomeni A. F. \& P. M. Mapongmetsem (2016) Nwegueh Bekwake A., Noutcheu R., Siergfried Dibong D., Tchatat M. and G. Fawa. 2016. Valorization of non-timber forest products in MayoRey (North Cameroon). Journal of Applied Biosciences, 108, 10491-10499.

[6] Oyen L. P. A. Bombax costatum Pellegr. \& Vuillet. [Internet] Fiche de PROTA4U. Brink, M. \& Achigan-Dako, E. G. (Editeurs). PROTA (Plant Resources of Tropical Africa / Ressources végétales de l'Afrique tropicale), Wageningen, Pays Bas, 2011. <http://www.prota4u.org/search.asp >.

[7] Arbonnier M. Arbres, arbustes et lianes des zones sèches d'Afrique de l'Ouest. CIRAD/MNHN/UICN, 2000, 539 p.

[8] Nacoulma-Ouédraogo O. G. Plantes médicinales et pratiques médicinales au Burkina Faso. Cas du plateau central. Thèse de Doctorat d'Etat ès Science Naturelle, Université de Ouagadougou, Tome I, 1996, 320 p.

[9] Coock J. A., VanderJagt D. J., Pastuszyn A., Mounkaila G., Glew R. S., Millson M. \& R. H. Glew (2000) Nutrient and chemical composition of 13 Wild Plant Foods of Niger. Journal of Food Composition and Analysis, 13, 83 - 92.
[10] Guinko S. Végétation de la Haute Volta. Thèse de Doctorat d'Etat ès Science Naturelle Université de Bordeaux III. France, 1984, 394 P.

[11] Belem. B. Ethnobotanique et conservation de l'espèce Bombax costatum Pel. \&Vuil. (Faux kapokier) dans les systèmes de production agricoles du plateau central, au Burkina Faso. Thèse de Doctorat, 2009, 189 p.

[12] Belem B., Boussim J., Bellefontaine R. \& G. Sita (2008) Stimulation du drageonnage de Bombax costatum par blessure des racines au Burkina Faso. Bois et Forêt des Tropiques, 295 (1), 71-79.

[13] Mapogmetsem P. M., Djomba E., Guidawa Fawa, Oumarou Z. \& R. Bellefontaine (2016a) Vegetative propagation of Vitex doniana Sweet. (Verbenaceae) by root segments cuttings: effects of mother tree diameter and sample distance of cuttings. Journal of Agriculture and Environment for International Development, 110 (2), 293306.

[14] Mapongmetsem P. M., Sounou Alium P., Raouguedam J., Koye Bava L. \& G. Fawa (2016b) Vegetative propagation of Sclerocarya birrea (A. Rich.) Hochst. from root segments cuttings: effect of substrate and root diameter. Annals of Experimental Biology, 4 (2), 23-32.

[15] Mapongmetsem P. M., Fawa G., Noubissie-Tchiagam J. B., Nkongmeneck B. A., Biaou S. S. H. \& R. Bellefontaine (2016c) Vegetative propagation of Vitex doniana Sweet from root segments cuttings. Bois et Forêts des Tropiques, 327 (1), 29-37.

[16] Mapongmetsem P. M., Djomba E., Fawa Guidawa, Oumarou Z., Dangai Yohana \& Bellefontaine R. (2017) Végétative propagation of Vitex doniana Sweet from root segments cuttings: effects of substrate and length of cuttings on the Rooting Ability. Annals of Experimental Biology, 5 (1), 1824.

[17] Oumarou Z. H., Hamaya Y., Tsobou R., Abdoulaye H., Bellefontaine R. \& P. M. Mapongmetsem (2018) Multiplication végétative de Securidaca longepedunculata Fresen par bouturage de segments de racine, Afrique Science 14 (6), 388-399.

[18] Ministère de l'Environnement et des Forêts (MINEF). Diagnostic de l'environnement. Sommet Mondial de Rio, 1994, 113 p.

[19] Letouzey R. Phytogéographie $d u$ Cameroun. Edition Lechevalier, 1968, $518 \mathrm{p}$.

[20] Mapongmetsem P. M., Tchotsoua M., Duguma B., B. A. Nkongmeneck (2000) Some strategies for reversing Adamaoua highlands degradation. Rev. Anthropos, 5, 107126.

[21] Yonkeu S. Végétation des pâturages de l“Adamaoua (Cameroun): écologie et potentialités pastorales. Thèse de Doctorat. Univ. Rennes I, France, 1983, 207p.

[22] Correa L., Paim D. C., Schwambach J. \& A. G. Fett-Netto (2005) Carbohydrates as regulatory factors on the rooting of Eucalyptus globulus labill. Plant Growth Regulation 45, 6373.

[23] Fisher E. H. \& Stein E. A. Biochemical preparation, 1961, 8. 30 p. 
[24] Leakey R. R. B., Mesen J. F., Tchoundjeu Z., Longman K. A., Dick J. McP., Newton A., Matin A., Grace J. et al. (1990) Low technology techniques for the vegetative propagation of tropical trees. Commonweath Forest Review, 69 (3), 247-257.

[25] Ky-dembele C., Mulualem Tigabu J., Bayala P., Savadogo J., Issaka Boussim \& P. C. Odén (2010) Clonal propagation of Detarium microcarpum from root cuttings. Silva Fennica, 44 (5), 775-786.

[26] Mapongmetsem P. M., Djoumessi M. C., Tonleu Yemele M., Doumara G. D., Fawa G., Noubissie Tchiagam J. B., Avana Tientcheu M. L. et Bellefontaine R. (2012b) Domestication de Vitex doniana Sweet. (Verbenaceae): influence du type de substrat, de la stimulation hormonale, de la surface foliaire et de la position du nœud sur l'enracinement des boutures uninodales. Journal of Agriculture and Environment for International Development - JAEID, 106 (1), 23-45.

[27] Stenvall N., Piisilä M. \& P. Pulkkinen (2009) Seasonal fluctuation of root carbohydrates in hybrid aspen clones and its relationship to the sprouting efficiency of root cuttings. Canadian Journal of Forest Research, 39 (8), 1531-1537.

[28] Bartolini G., Pestelli P., Toponi M. A. and Di Montez G., 1996. Rooting and carbohydrate availability in Vitis 140 Ruggeri stemcuttings. Vitis 35 (1): 11-14.

[29] Preethi D., Sridhar T. M. \& C. V. Naidu (2011) Carbohydrate Concentration Influences on In Vitro Plant Regeneration in Stevia rebaudiana. J. Phytol. 3 (5), 61-64.

[30] Oka S. \& K. Ohyama (1986) Mulberry (Morus alba L.). Biotechnol. Agric. For. Trees I, 384-392.
[31] Pitekelabou R., Aïdam A. V. \& K. Kokou (2015) Influence of various carbohydrates on the in vitro micropropagation of Nauclea diderrichii (De Wild \& T. Durand) Merrill, an endangered forest species in Togo. African Journal of Biotechnology, 14 (15), 1283-1289.

[32] Xing W., Bao M., Qin H. \& G. Ning (2010) Micropropagation of Rosa rugosa through axillary shoot proliferation. Acta Biologica Cracoviensia Series Botanica, 52 (2), 69-75.

[33] Hoad S. P. \& R. R. B. Leakey (1996) Effects of pre-severance light quality on the vegetative propagation of Eucalyptus grandis W. Hill ex. Trees Structure and Function, 10, 317.

[34] Robinson J. C. \& W. W. Schwane (1977) Studies on the regenaration of apple cultivars from root cuttings. II. Carbohydrate and auxin relations. Journal of Horticultural Science, 52, 221-233.

[35] Cameron R. J. and G. V. Thomson (1969) The vegetative propagation of Pinus radiata: root initiation in cuttings. Botanical Gazette, 130, 242-251.

[36] Puri, S. and G. S. Shamet (1988) Rooting of stem cuttings of some social forestry species. Intl. Tree Crops J., 5, 63-70.

[37] Tchoundjeu Z. \& R. R. Leakey (2001) Vegetative propagation of Lovoa trichioides: effect of provenance, substrat auxine and leaf area. Journal of Tropical Forest Sciences 13 (1), 16129.

[38] G. A. Couvillon (1988) Rooting responses to different treatments. Acta Hort., 227, 187-197. 